\title{
(2) \\ Healing Traditions of Southern India and the Conservation of Culture and Biodiversity: A preliminary study
}

\author{
Todd J. Pesek, Lonnie R. Helton, Ronald \\ Reminick, D. Kannan and Murali Nair
}

\section{Research}

\begin{abstract}
A comparative study on regional traditional healing and community wellness provision in collaboration with traditional healers was conducted in three distinct ecological regions in the southern Western Ghats, India. The study led to the collection of data, from fourteen healers, on their healing systems, local afflictions and modes of treatment, community roles of healers, and adaptations of the respective populations to their environments via traditional healing. Key points emerging from these qualitative data include a general consensus among healers which preliminarily illustrates intact healing traditions, a keen healer and community interest in programming focused on the conservation of biodiversity and culture for sustainable, traditional wellness promotion, and that in sustaining health there must be healthful environmental surroundings.
\end{abstract}

\section{Introduction}

Traditions of ancient civilization and knowledge, much of which is common knowledge in the state of Kerala (Haliburton 2002), regarding the nature of health and wellness, are prevalent in contemporary India. We can learn from these traditions on a variety of levels to address a number of contemporary needs in health and wellness for both people and planet.

Thousands of years ago Indian practitioners began evolving the art of healing. In many of their ancient writings, healers discussed a variety of modalities for healing a person's body, mind, and spirit. For example, the Charaka Samhita, believed to have arisen some 2300 years ago, is thought to be one of the oldest and most important ancient authoritative writings on ayurveda, one of the main traditional healing systems of India (Ministry of Health and Family Welfare 2007).
It seems likely that ayurveda was, in part, influenced by Buddhist philosophy (Liyanaratne 2001). It also seems likely that ayurveda in turn inspired or influenced other healing systems (Liyanaratne 2001, Scharfe 1999) including: Siddha, another prominent but less well known healing system of India (Scharfe 1999, Ministry of Health and Family Welfare 2007, Vaidyar 2007); Unani, another of the larger learned systems in India, but with Mediterranean roots (Ministry of Health and Family Welfare 2007); and traditional Chinese medicine (Liyanaratne 2001). Of the Indian healing systems, ayurveda is certainly the most widespread and well-known practice, and, though debated, likely the oldest (Scharfe 1999).

In the south of India, the two main traditional healing systems practiced today are ayurveda and siddha. Siddha predominates in the southern Western Ghats region (Pesek et al. 2007c). In addition to these main learned systems, however, there are a multitude of diverse tribal healing systems throughout the south (Pesek et al.

\section{Correspondence}

Todd J. Pesek, Department of Health Sciences, Cleveland State University, Cleveland, Ohio, U.S.A.

t.pesek@csuohio.edu

Lonnie R. Helton, School of Social Work, Cleveland State University, Cleveland, Ohio, U.S.A.

Ronald Reminick, Department of Anthropology, Cleveland State University, Cleveland Ohio, U.S.A.

D. Kannan, Center for Environmental Studies, Amrita Vishwa Vidyapeetham University, Coimbatore, Tamil Nadu, INDIA.

Murali Nair, School of Social Work, Cleveland State University, Cleveland, Ohio, U.S.A.

All authors part of: Center for Healing Across Cultures, Cleveland State University, Cleveland, Ohio, U.S.A.

Ethnobotany Research \& Applications 6:471-479 (2008)

Published: December 30, 2008 
2007b). These diverse tribal systems are especially well represented in the mountainous Western Ghats regions (Pesek et al. 2007b). This finding is in keeping with the fact that, globally, cultural diversity is maintained most prominently in mountainous areas (Steppe et al. 2005). These tribal systems are reflective of both original and derivative themes in ayurveda, and the subsequent schools of thought derived from ayurveda, all of which teach the integrated healing of mind, body, and spirit through the promotion of natural harmony, balance and a close connection with nature (Nair et al. 2007b, Pesek et al. 2007b).

Regardless of the beginnings of ayurveda, siddha or other healing systems, these Indian healing traditions have evolved in a variety of environmental micro-niches to yield a variety of practices. It is highly likely that the concepts developed through the process of shared learning about and in close communion with the environment gave rise to efficacious, appropriately tested, and unifying practices (as given in the present study by general consensus). These complex healing systems rely on first identifying imbalance and then correcting the imbalances through a variety of mechanisms including diet and lifestyle modifi-

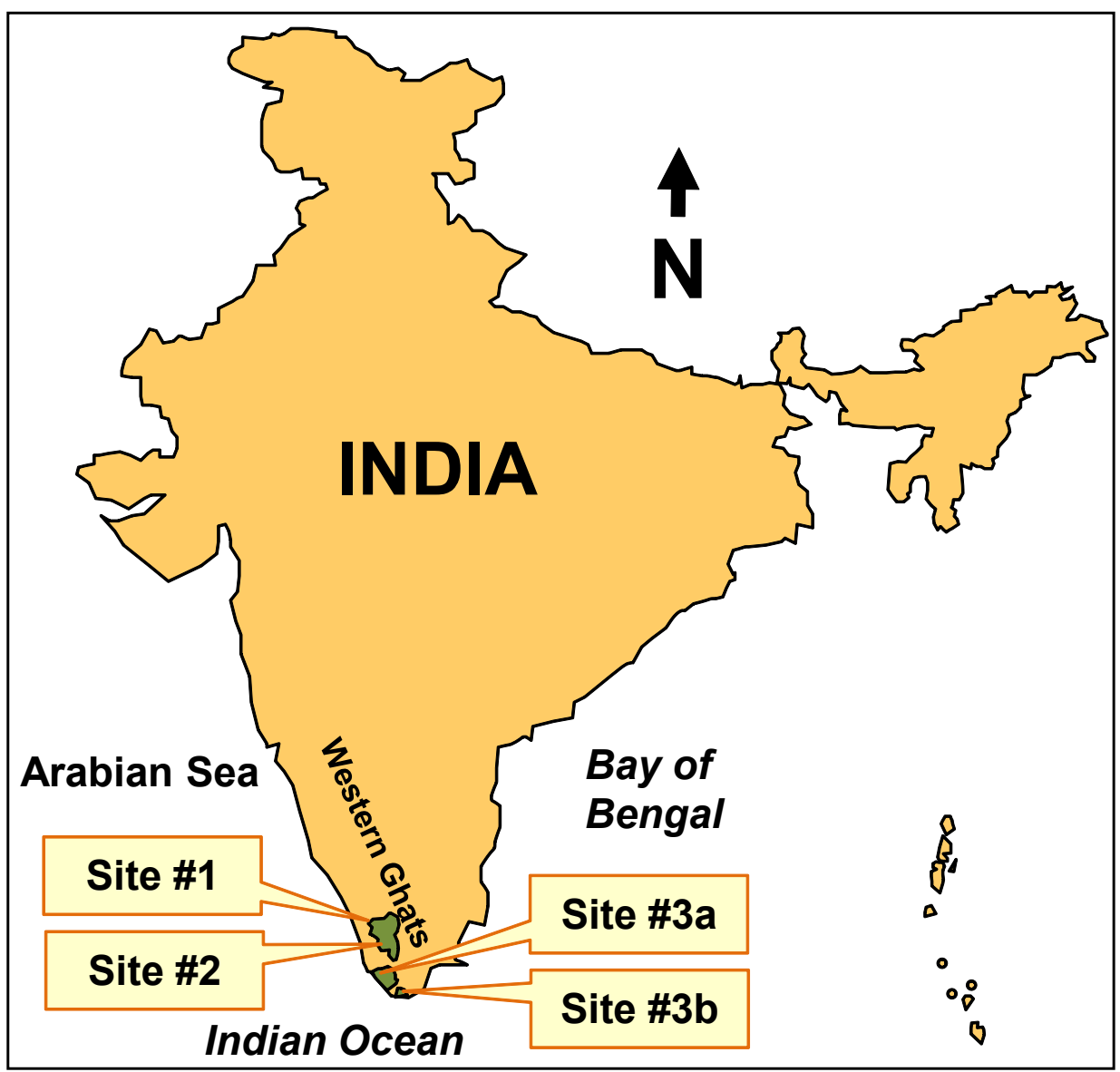

Figure 1. Study sites in South India. Site \#1: Region of Koodakadu village, montane evergreen forest; Site \#2 Region of Kulamavu Kuzhi village, moist deciduous forest; Site \#3a Thiruvanathapuram, and Site \#3b Kanyakumari, backwaters and coastal regions. cations, connection to nature, and detoxification by a variety of modalities including herbal therapies.

\section{Regional Overview}

The regions of southern India are varied, but fall mainly into mountainous and coastal categories based on varied topography. The Western Ghats (Sahyadri in Sanskrit) is a mountain range in southwestern India. Running northsouth, it represents the western border of the Deccan Plateau, a large plateau which makes up much of southern India. The mountains separate the plateau from a coastal plane which borders the Arabian Sea.

With peaks above $1800 \mathrm{~m}(6,750$ feet) and an average elevation of $900-1200$ m (Karnataka Forest Department 2007, Kerala Forests and Wildlife Department 2007) the range runs almost parallel to the Arabian Sea from north to south through the states Maharashtra, Karnataka, Goa, Kerala and Tamil Nadu (Karnataka Forest Department 2007, Kerala Forests and Wildlife Department 2007). Running approximately $1800 \mathrm{~km}$, the range covers 60,000 sq. km. It is a substantial portion of catchment drainage to all of India (Karnataka Forest Department 2007, Kerala

Forests and Wildlife Department 2007). The rivers flowing from the mountains form complex ecologies in the coastal plains and lead to a series of brackish lagoons and freshwater lakes called backwaters. These are in Kerala, one of the two southernmost states of the Indian subcontinent, the other being Tamil Nadu. Approximately $450 \mathrm{~km}$ of the Western Ghats run through Kerala covering nearly $21,856 \mathrm{sq}$. $\mathrm{km}$. This is $56 \%$ of the total geographical area of the state (Kerala Forests and Wildlife Department 2007). It is Kerala and the adjacent southern portion of Tamil Nadu, on which we focus our study because they are regions that are intersections of complex ecologies, biodiversity, and culture (Figure 1).

Geographically, the area can be divided into three regions based on approximate topography: highlands, midlands and low- 


\section{Pesek et al. - Healing Traditions of Southern India and the Conservation of Culture and Biodiversity: A preliminary study}

lands. The highlands include the upper reaches of the Western Ghats and are well represented by montane evergreen type forests at higher elevations and moist deciduous forests at lower elevations interspersed with plantations of tea, coffee, rubber, sandalwood, and cardamom. The midlands region is made up of moist deciduous forests with undulating hills and valleys and is an area of intensive agriculture of cashew, coconut, cassava, banana, rice, ginger, pepper, sugarcane and a variety of vegetables. The lowlands produce coconut and rice. They are made up of river deltas and backwaters and abut the Arabian Sea to the west and the Western Ghats to the east.

The Western Ghats and adjacent backwaters areas of Kerala support a large area of varied tropical rainforest ecosystems. Given model conservation practices the ecosystems are well intact and diverse. However, as elsewhere in the world, they are pressured by human exploitation. There is $11,221 \mathrm{sq}$. km. of forest area in Kerala representing $28.9 \%$ of the area of the state (Bhandari \& Kale 2007). Floral diversity of the area is supported by numerous factors including high levels of regionally focused precipitation, $2,604 \mathrm{~mm}$ annually, complex elevation differentials, rain shadow effects and unique geomorphologic variation of the Western Ghats (Bhandari \& Kale 2007, Kerala Forests and Wildlife Department 2007). Indeed, the Western Ghats are a biodiversity hotspot (Myers et. al. 2000).

The Western Ghats range intercepts the monsoon winds from the Arabian Sea which thus dump their precipitants onto the western slope of the Western Ghats range which experiences heavy rainfall relative to the eastern slopes. Rainfall also decreases from south to north.

There are two predominant ecosystems in the Western Ghats: a high elevation montane evergreen rainforest and moist deciduous rainforest at the lower elevations. The mountainous Western Ghats provides for the maintenance of rich cultural traditions in the area. As mentioned, a phenomenon in keeping with trends internationally; traditional cultures persist in mountainous regions (Stepp et al. 2005). Complementing this cultural diversity, are, rich, intact traditional healing systems adapted to their respective habitats (Pesek et al. 2007b).

The government of India has entered into a variety of innovative co-management scenarios with these inhabitants to ensure sustainable land management. Indian governmental policies are perhaps a response to the threat to our planet's biodiversity which is being lost at an unsustainable rate (Hanski 2005, United Nations Food and Agricultural Organization 2005, World Wildlife Fund 2004). These rates of destructive patterns on our rainforests are unsustainable. It is also known that these forces arise from complex human needs including local peoples' resource exploitation and exchange practices as well as more far reaching economic patterns. Additionally, the ecologies and diverse cultures are disappearing because of the encroachments of Western culture and modernizing influences. Languages, taken as a marker to cultural diversity, indicate rapidly accelerating cultural extinction by parallel trends in language (Buenz 2005, Maffi 2001a,b, Sutherland 2005). Of the 15,000 languages spoken 70 years ago, only 6,000 are still spoken today (Buenz 2005, Davis 1999, Grimes 1996, Maffi 2001b, Sutherland 2005).

\section{Healing Traditions of Southern India}

Given the biocultural diversity of southern India, it becomes difficult to offer here a complete representation of the regional healing traditions. However, we can realistically identify the general categories of traditional healing systems as represented by regions which bore their knowledge through the millennia of shared learning in the context of their respective environments. Thus, we selected for study and comparison, three representative populations based on regional and ecosystem differences: 1) higher elevation Western Ghats or montane evergreen forest, 2) lower elevation Western Ghats or moist deciduous forest, and 3) backwaters, including lowland and coastal regions. We then examined and compared village populations via representative, prominent, well-respected traditional healers.

\section{Study Sites Within the Target Regions}

Marayoor town and Valara town of Idukki District, Kerala were the small towns in close juxtaposition to where we began our work in remote Western Ghats villages. Idukki, a land-locked district of Kerala, is one of the most biodiverse areas of Kerala (Kerala Forests and Wildlife Department 2007), known for its mountainous terrain and dense forests. About $50 \%$ of its area is reserved forests. The name Idukki has been derived from the Malayalam word idukku meaning "narrow gorge". Located in the southern part of Kerala, it is spread over an area of 5019 sq. km (Kerala Forests and Wildlife Department 2007).

\section{Site 1: Montane Evergreen Forest}

We selected a large settlement, Koodakadu village, $\sim 1600$ m elevation, outside of Marayoor (same elevation), a rural town $40 \mathrm{kms}$ from Munnar, also $1600 \mathrm{~m}$ in elevation, Idduki district, Kerala, India. According to the tribal elder there, who is an administrative official similar to a mayor, there are forty-one healers who serve a population of approximately twenty thousand in the region. We selected six representative healers and three of their four apprentices for interviews at Marayoor. The predominant tribal people in Marayoor are the Muthuvas and thus the six healers we interviewed were Muthuvas.

The forest type around Koodakadu village was montane evergreen forest with emergents of up to $30-40 \mathrm{~m}$ and a Cullenia spp. prevelance, with many other members of 
the Malvaceae; Tectona grandis L.f., Verbenaceae; numerous genera of Dipterocarpaceae; native Santalum album L., Santalaceae (sandalwood) as well as a number of other notable medicinal species including Trichopus zeylanicus Gaertn., Dioscoreaceae (arogyapacha in Malayalam meaning "the green that gives strength"), and Withania somnifera (L.) Dunal, Solanaceae (ashwagandha in Sanskrit meaning "horse smell" for the smell of the root of Indian Ginseng). Several tribal communities inhabit this region including the Muthuvas as well as Ulladan and Elipillayar.

\section{Site 2: Moist Deciduous Forest}

Kulamavu Kuzhi village outside of Valara $(\sim 800 \mathrm{~m}$ in elevation), a rural town $10 \mathrm{kms}$ from Munnar (1600m in elevation) where we selected 3 representative healers and their 3 apprentices for interview. At Valara, the Muthuvas and Uraly people predominate as the two largest groups in a ratio of approximately $8: 1$. There are roughly 80,000 Muthuvas and 9,000 Uraly in the region. We interviewed 2 representative healers of the Muthuvas and 1 representative Uraly healer.

The forest type around Kulamavu Kuzhi was moist deciduous with notably tall emergents of up to $50-60 \mathrm{~m}$. Bridelia spp., Phyllanthaceae and Pterocarpus spp., Fabaceae were well represented and there were numerous genera of Malvaceae including Theobroma cacao L. (cacao or chocolate), as well as numerable Sterculia spp. and Pterospermum spp. There were also concentrations of Piper spp., Piperaceae, including Piper longum $L$. and $P$. nigrum $L$. and the important ayurvedic medicinal plant Terminalia arjuna Wight \& Arn., Combretaceae was also present.

\section{Site 3: Backwaters including Lowlands and Coast}

We selected two well known representative healers from Backwaters regions of Thiruvananthapuram District and three well known representative healers from the region around Kanyakumari, a coastal town in Kanyakumari District, Tamil Nadu state. Located at the southernmost tip of peninsular India, it is the southern-most stretches of the mainland Western Ghats.

The flora in these regions was highly varied. There were diverse grasses, sedges and mosses as well as palm and mangrove species. The important medicinal plants Azadirachta indica A. Juss., Meliaceae (neem) and Myristica fragrans Houtt., Myristicaceae (nutmeg and mace) were well represented.

\section{Research Methodology}

Our study methodologies and informed consent protocol was approved by the Institutional Review Board of Cleveland State University, Cleveland, Ohio, USA.

To begin our fieldwork, we held two international symposia at local universities on the topic of: healing across cultures and learning from traditions of India. These university based symposia were held at Loyola College of Social Sciences, Kerala, India, and Amrita Vishwa Vidyapeetham University, Coimbature, Tamil Nadu, India. There were then a series of community-based workshops which continued the discussions of these symposia in the local communities and with the local healers of the selected study sites. These workshops addressed multitude issues, both short- and long-term including: health and wellness practices, community needs, social and environmental justice issues etc. The particulars of the present study were discussed in detail at these community-based workshops.

A uniform practice of open-ended queries to include discussion and concepts on general areas of mind, body, spirit, and environment in health, healing, and community wellness was used in both formal and informal interview processes at each location and with each healer. The specific topics covered included health and wellness practices, community needs, social and environmental justice issues. Spontaneous queries and conversation were lively and fruitful. The interview information was recorded by three of the researchers so that triangulation via comparison of notes could be done later to include data missed by one recorder but picked up by another. Two of the researchers were Indian and served the very important roles of translator, researcher and cultural broker. They introduced the research group to the tribal peoples and translated Malayalam and Tamil. They also provided interpretations when the meanings of ideas or attitudes were ambiguous. A component of our analysis included identifying themes running through conversations. At least three healers were interviewed in each of the three representative sites and we interviewed their apprentices when possible. We interviewed the healers in field and forest as well as in their clinics and local village settings. We also observed the healers with village officials, patients and apprentices.

We discussed the lives of the healers, their cosmologies and practices and prevailing attitudes toward their profession. We talked about the resources with which they work, their successes and failures in practice, and the obstacles to their treatment modalities they had to deal with. We felt it was also important to get an idea of the range of variation of afflictions as well as the commonalities in treatments. What the healers were especially concerned about was the uncertainty of the transmission of healing knowledge to the next generation and the increasing problems 


\section{Pesek et al. - Healing Traditions of Southern India and the Conservation of Culture and Biodiversity: A preliminary study}

with the local resource exploitation and the disappearance of resources.

Specimens representing the species discussed in this paper were identified on site by local flora expert Dr. D. Kannan and verified where necessary with collections at the Center for Environmental Studies, Amrita Vishwa Vidyapeetham University, Coimbatore, Tamil Nadu, India. Plant species are provided within this document generally to develop the differences between the environmental areas for the benefit of the reader.

\section{Preliminary Results and Discussion}

The body of qualitative data collected from the three sites was grouped into ten major categories for analysis: 1) definitions of healing and healing ideologies; 2) the role of the healer; 3) teaching of the healing practices; 4) the range of illness types treated; 5 ) the types of appropriate treatments; 6 ) herbal preparation methods and associated rituals; 7) rituals carried out in the treatment process; 8) the frequency of patient visits; 9) the costs involved in treatments; 10) obstacles to the practice of traditional healing. The healers were forthcoming in relating their healing ideologies across the study sites which were the montane evergreen forest area, the moist deciduous forest area, and the backwaters and coastal area.

\section{Study Site 1: Koodakadu Village, Montane Evergreen Forest}

The healers at the first site, a more rural and isolated village high in the Western Ghats, talked about reciprocal healing of patients and earth. They focused heavily on spirituality and the spirits of plants in the healing process. They emphasized treading lightly while giving thanks and focused effort to the betterment of the community as a more collective entity. They focused their healing treatments for physical ailments on plants and herbs, steam bathing and a sauna-like treatment for detoxification. They had separate spiritual and herbal healing practices. Their deity worship varies but includes Eswaran, another name of Lord Shiva, Ganapathy, Murugan, Kali and Avatharam of Parvathi Devi.

Their spiritual healing practices were held most sacred. These practices are safeguarded and passed only from father to son. Only about half the healers were spiritual healers and there were a few who were actively learning the spiritual healing rituals and ceremonies from them. The physical healing with herbs and steam baths and sauna practices was more freely taught. Mostly to sons, however, other community males and occasionally females were taught. There is a significant amount of ritual in collecting the plants for the healing. Most often fresh plants are used as frontline agents with dried plants being used after frontline therapies or when fresh plants are not available. Water is integral to healing in their practices. They also placed much emphasis on the strong mind and meditative and mantra practices in both healing and being healed. The healing strength of a strong mind was an important theme. Healing comes from the earth and from balance. This supports the strength of the mind. These healers were concerned about the disappearance of forests. They maintain that there are ways to work with the forest in life and healing in sustainable fashion. They asserted that they have done this for generations and that the forest is sacred and we are a part of the forest. "We must nurture it as it nurtures us. To those who do not know this, we must teach them. This is in part our responsibility as we must teach our children the healing ways." There is strong interest among the youngsters in this community to learn the healing ways. They have implemented a program for training youngsters the healing ways. In this program each apprentice spends time with each of the healers and continues to rotate time with them. This practice is working well for them in training their next generation. They consider this effort a success, however, their knowledge is tied to the forest which must be protected to continue the cycles of knowledge. There are a number of sustainablility practices that have been embedded in their traditions and these are viewed as integral to balance and healing. They strongly advocate for forest protection, regeneration, and community gardens for the species that they rely upon.

\section{Study Site 2: Kulamavu Village, Moist Deciduous Forest}

The healers dwelling in the moist deciduous forest region discussed respecting the spirit of the plants as well, yet they were more connected with larger society. They discussed ongoing interactions and collaboration with healers outside their communities. They felt strongly as well that there were physical and spiritual necessities to health, and that there were separate spiritual and herbal healing practices as well. These people talked of health from the forest and that it provided all that they need in healing. The people who have moved away from the forest seek out these healers. These healers harvest their medicines from the forest and use mostly fresh plants. They run dispensary- type setups and have noted their efforts to sustain resources for all their patients. But they also stated that there needed to be sustainable practices set. They expressed concern about several important species becoming endangered because of unsustainable use. They discussed individual gardens, but suggested that community gardens would not work given the individualized nature of their practices. However, they recognized that a community plot in conjunction with separate more individualized house gardens might work. They emphasized diet in healing and have a system of healing with foods and certain dietary exclusions in healing. They maintained that there was interest among their youngsters to learn, but that it was hard to continually engage them. A small sti- 
pend for living expenses would go a long way in providing practical measures for their study and practice. This was one stumbling block cited by several apprentices.

\section{Study Site 3: Backwaters and Coastal Regions, Thiruvananthapuram and Kanyakumari}

The healers of the backwaters and coastal regions talked about the healing powers of the sun, moon, and stars and they shared amongst each other specific healing practices such as herbal remedies, meditative and stretching practices, mud baths, steam treatments, and marmum or the application of touch and pressure to series of points on the body. Interestingly, these healers had herbal gardens in operation. There was a good deal of ritual involved in the preparation of medicines. Sometimes it took weeks to make certain types of medicines.

One healer who proudly demonstrated the growing and preparation of herbal remedies from his garden had a palm leaf with etched marmum points that had been handed down through five generations of healers in his family. He indicated that he has twelve assistants who work with him regularly one of whom is a devoted apprentice. Apprentices are not paid while they are learning and are not allowed to practice without the direct tutelage of their teachers. A healer in the backwaters area had grown herbs continuously for 45 years and used them for a range of healing practices. His garden now consists of 67 domesticated species. He had a specific dandruff remedy which was curative and he treated the gamut of ailments from stomach problems and headache to snakebite and other serious conditions with common species such as Aloe vera (L.) Burm. f., Zingiber officinale Roscoe (ginger) and Piper spp. (pepper) including $P$. longum and $P$. nigrum, Curcuma longa L. (turmeric) mixed in elaborate pastes with little known medicinal plants from his gardens which he domesticated to serve his patients. He discussed the importance of balance in health. He learned the practice of marmum after 10 years of study with his father and also learned a type of self defense bearing resemblance to yoga and kalarippayat. He was clear in stating that his garden was born out of his efforts to preserve the precious medicinal species that he knows. Some of these plants grow only near lakesides. Modernization has eradicated more than a dozen species that he can specifically recall and at least forty other extremely important healing plant species are becoming more and more rare. He was taught how to use 4,448 plants in healing. He uses a fraction of these today due to availability. Healers in the backwaters region use different metals and mineral compounds by preparing them with herbs and employ a burning and baking process, after which the mineral is ground into a powdered medication. It takes 21 days or more to make these types of medicines, which are then used in small doses. In the coastal backwaters region healers shared specific healing practices and rituals. The garden healer took the researchers into his garden and also to the coastal waters area from which he had transplanted his herbal plants. He demonstrated the drying of these herbs and discussed in some detail the drying, mixing, and preparation rituals involved in making his medicinal cures. The Marmum healers demonstrated their healing techniques using willing participants. Having learned Marmum from his father and uncle, one healer started his apprenticeship at age 15. This type of Marmum healing involves a combination of herbs, touching points, and other rituals. He identified 12 healing points and 96 touching points which he was taught by his father. One "point" or meridian goes from head to tailbone. One of the most important points is located between the eyes at the "ajna". The healing rituals avoid touching on this point. One healer noted, moreover, that all diagnosis is confidential and affirmed that he would not take money for his services. He said that treatment of the sick always brings blessings to the healer. The marmum healer uses the ayurvedic principles of pitha, vatha, kapha. The pulse at each of these loci on the inner left wrist is accessed in 15 seconds or so. Only the left hand is used to take the pulse. Touching a person is necessary for diagnosis. Medicine is given by the healer "singing in his mind." The Marmum healer also stated that patients with emotional problems often do not need medicine so he gives them a placebo.

\section{Relative Consensus Among Sites}

There was a relative consensus among healers at each site suggesting intact traditions in their respective regions. However, this general consensus was most pronounced at Sites 1 and 2. As well, there were several recurrent themes across the three sites suggesting a general consensus about certain efficacious traditional healing practices. We discuss some of these in the following paragraphs.

The ultimate purpose of the healer is to serve humankind. Healers must be of "good character" which means they must be neutral and balanced. Healers are blessed. One notable overriding theme was that "a true healer is an earth healer." The apprentices must be intelligent, motivated to learn and practice what they learn. Only family members, generally sons, are taught the art of spiritual healing. All healers have respect for the world around them, that is, all forms of life (human, animal, and plant life as well as the natural world). The reciprocal interaction of mind, body, and spirit within a healthful and life sustaining natural and social environment, as defined by Pesek et al. 2006b, was a recurring theme across the various healing traditions explored in southern India. Healing traditions are brought to the younger generation through careful selection of the apprentices. They are taught sustainable ways of maintaining the land and resources, including reforestation and appropriate sharing and marketing of healing plants and minerals. 


\section{Pesek et al. - Healing Traditions of Southern India and the Conservation of Culture and Biodiversity: A preliminary study}

Healing is manifest with both spiritual and herbal practices. Some healers assume both roles. Most healers see approximately twenty patients a day, though one healer asserted that 200-300 patients report to his dispensary on a daily basis. The healing sessions usually range from $20-$ 30 minutes, but tissue damage usually takes more time as it requires manipulation. They require a rather strict dietary regimen, which if not followed, may result in continued sickness or relapse. They administer herbs, metals, minerals, steam bathing, certain medicines orally and through the nose and they practice a number of manipulation techniques including the marmum practices. Healers agreed that the process of teaching one to become a healer takes six to seven years. Herbal healers are considered to be specialists and may refer patients to other healers of different specialties.

Healing practices are learned from one's parents, grandparents, or other elders. Healing traditions include learning how to identify herbs, preparation and identification of proper medicinal dosages, and the practice of spiritual chanting and other rituals used in the healing process. Sons are the preferred apprentices as they tend to be the closest to the father and most eager to learn. But one healer said that he taught his two daughters. Spiritual healing, however, is taught only to sons and must be learned separately from other healing practices.

The healers were willing to talk openly about their fees. The fees range from no charge to fifty or sixty rupees for a single dose (40 R's = 1 US\$). Examples of illnesses that might be treated with a single dose included high blood pressure and diabetes. Men and some women come for such treatments and an extraordinary ten thousand rupees may be charged.

Understandably, the healers must first identify imbalance or make a diagnosis before treating an imbalance or illness. This imbalance or illness determines the length of treatment. Healers often work together, treating the same patients depending on the patient's illness and specific needs. Healers have stated that certain medicines, when given in a single dose, could resolve respective illnesses. As noted earlier, fresh herbs are important for use at the outset of treatment; after that, dried herbs can be used. Herbs dried are always dried in the sun. The ritual involves the healer saluting the sun. The healer closes his eyes and prays. For every ailment there is a god or goddess who may be called on for assistance.

Illnesses of the blood, such as jaundice, need longer treatment. Water is often used in treatment. This is also found among other cultural groups. Steam and oils are also used for treatment, the steam bath being given with the patient under a blanket. Bandages are used over broken bones and herbs are applied directly to the injury. Massage is used to enhance the healing process and alleviate pain.
The healers identified over twenty-five illnesses they treat on a regular basis. These included hypertension, diabetes, skin diseases (like psoriasis), asthma, arthritis called "swollen knees", cancer, healed if treated in early stages, snake bite (including cobra), immune system deficiencies including AIDS, stomach problems, stomach ulcers, indigestion, tissue damage, mental illness, diabetes, ligament tears, hair loss, bacterial infections, fever, liver problems, poison, and eye problems. Mental illness is treated by using select herbs and stuttering is treated by putting certain juices on the tongue. A recurring theme among the healers was the assertion that some $80 \%$ of those treated are healed; those not healed did not follow the prescribed diet and treatment regimen.

The healers identified several obstacles to their healing practices and the continuation of their work. Travel is involved in outreach, to reach patients in distant places one needs transportation. Also, they discussed the need for forest preservation and regeneration techniques. They are actively doing these things and are willing to teach others. They need designated land to cultivate their gardens. There is financial scarcity in accessing resources necessary for growing the medicinal herbs for treatment. They want to be able to continue to grow herbs locally and process them from their own gardens. There is a pronounced need for training the youngsters. They feel that by working on forest regeneration and regrowth projects as well as individual and community gardens they will be better able to treat patients and train youngsters.

\section{Conclusions and Future Directions}

The ancient Indians were the custodians of a highly evolved civilization with great awareness of the decisive importance of humanity's respect for and maintenance of our natural environment. Today's healers are well aware of the vulnerability of both humankind and our natural environment. This wisdom has been propagated to contemporary peoples including Indian healers and sages who consider human health from the point of view of mind, body, spirit, and environment with both social and natural components (Pesek et al. 2006b). In modern society, there is an ever-growing disconnection from the natural world. This is worrisome because we are constituents in nature and as such are inextricably connected and dependent on nature for our health. Since time immemorial, people have enhanced their own health by immersion in thermal pools of water and mud, steam bathing, engaging in physical and mental exercise, by eating healthful foods including herbals, and by becoming enraptured in nature. Healers the world over have sensitized millions to humankind's inevitable connection to nature and nature's timeless nurturance of humankind. Cosmologies of ancient tradition and healers of past and present have maintained respect for their environment as a path to healthful living. It is this ecological adaptation allowing the accumulation of knowl- 
edge about habitat, food and medicinal resources, and one's relationship to nature that is the foundation for healing and is reflected in the healing traditions of India.

It has been noted that the preservation of tropical forests and the peoples who call the forest "home" can only be accomplished together (Arnason et. al. 2004). Good governance is also key to the success in conservation (Buenz 2005). One strategy in accomplishing this is the promotion of respect for and the integration of traditional healing into the national health care systems (Arnason et. al. 2004, Pesek et. al. 2006a,b Pesek et. al. 2007a, World Health Organization 2002).

Global health and wellness is greatly facilitated by traditional healing. More than $80 \%$ of the world population relies on traditional healing for primary healthcare (World Health Organization 2002) and greater than $25 \%$ of modern medical drugs stem from traditional healing knowledge (World Health Organization 2002). Science is beginning to discover what traditions have known for generations. It is time that we become more attentive to and learn from our traditions (Pesek 2006b).

A culturally appropriate approach to health improvement, conservation of culture and biodiversity, and economic development can be based on establishing an innovative health care partnership of traditional healers and rural health care providers supported by a sustainable small herbal products microenterprise (Nair et al. 2007a, Pesek et. al. 2007a). It could offer tribal and local communities in and around the Western Ghats regions significant opportunity for sustainable economic development based on the knowledge of medicinal plants and their relationship to the environment held by their traditional healers. This integrated program carried out under the guidance of the healers and local leaders will offer increased access to both traditional and contemporary health care, improve access to quality traditional medicines, and provide the opportunity for large-scale community-based conservation initiatives as well as sustainable "green business" platforms based on natural products which benefit local peoples.

Our research findings demonstrate strong possibilities for such programming in these regions. There is potential in terms of natural resources and bio-cultural diversity. There are strong traditions as demonstrated by general consensus and there is also willingness and need for the development of such initiatives in support of local and global health as well as in support of regional conservation programming. Such programming in the region could result in significant beneficial impacts on ecosystems, healthcare, and the development of model practices in sustainability, based on traditions that have proved relevant and meaningful in our contemporary world.

\section{Acknowledgements}

This work was supported by the Center for Healing Across Cultures, the Graduate College, the College of Liberal Arts and Social Sciences, and the College of Science, Cleveland State University, Cleveland, Ohio. Further support was contributed by the Center for Environmental Studies, Amrita Vishwa Vidyapeetham University, Coimbatore, India. The authors wish to express our deep appreciation to Dr. M. Aravindakshan, Coordinator, Center for Environmental Studies, Br. Abhayamrita Chaitanya, Chief Operating Officer, and Dr. P. Venkat Rangan, Vice Chancellor, Amrita Vishwa Vidyapeetham University for their in-country coordination and support. We would also like to express our gratitude to N. Viswanathan, Kerala Institute for Research, Training and Development Studies of Scheduled Castes and Scheduled Tribes, Kerala, India, and Br. Gnanamrita Chaitanya and Mrs. Rajini Menon, JSS Office at Nedunkandam for their invaluable assistance in the field. We would also like to thank Diana Llapa for her field service as our research assistant. We certainly are indebted to the traditional healers who so willingly and forthrightly gave of their time and attention to teach us about their professions and welcome us for further research. Finally, we would like to dedicate this work to Sri Mata Amritananda Mayi Devi, better known as "Amma" who has been a healer and an inspiration to millions of people around the world.

\section{Literature Cited}

Arnason, J, P. Catling, E. Small, P. Dang \& J. Lambert. 2004. Editors of Biodiversity \& Health: Focusing research to policy. NRC Research Press, Ottawa, Ontario.

Bhandari, L. \& S. Kale. 2007. Editors of Indian States at a Glance 2006-2007: Kerala: Performance facts and figures. Dorling Kindersley (India) Pvt. Ltd., licensees of Pearson Education, South Asia, New Delhi.

Buenz, E. 2005. Country development does not presuppose the loss of forest resources for traditional medicine use. Journal of Ethnopharmacology 100:118-123.

Davis W. 1999. Clouded Leopard. Vancouver, BC: Douglas and Maclntyre Publishing Group.

Grimes B. 1996. Ethnologue: Languages of the world. 13th edition. Summer Institute of Linguistics, Dallas.

Haliburton M. 2002. Rethinking anthropological studies of the body: Manas and Bodham in Kerela. American Anthropologist 104(4):1123-1134.

Hanski I. 2005. Landscape fragmentation, biodiversity loss and the societal response. EMBO Reports 6(5):388392. 


\section{Pesek et al. - Healing Traditions of Southern India and the Conservation of Culture and Biodiversity: A preliminary study}

Karnataka Forest Department, Government of India. 2007. www.karnatakaforest.gov.in/English/index.html November 2007

Kerela Forests and Wildlife Department, Government of India. 2007. www.keralaforest.org November 2007

Liyanaratne, J. 2001. Some Sri Lankan medical manuscripts of importance for the history of South Asian traditional medicine. Bulletin of SOAS 64(3):392-400.

Maffi, L. 2001a. Editor of On Biological and Cultural Diversity. Smithsonian Institution Press, Washington, DC.

Maffi, L. 2001b. Language, knowledge, and indigenous heritage rights. Pp 412-432 in On Biological and Cultural Diversity. Edited by L. Maffi. Smithsonian Institution Press, Washington, DC.

Ministry of Health and Family Welfare, Government of India. Department of Ayurveda, Yoga \& Naturopathy, Unani, Siddha and Homoeopathy (AYUSH). 2007. www.indianmedicine.nic.in/index.asp November 2007.

Myers N, R. Mittermeier, C. Mittermeier, G. da Fonseca \& J. Kent. 2000. Biodiversity hotspots for conservation priorities. Nature 403:853-858.

Nair, M., R. Brody \& A. Palackal. 2007a. Grassroots Development: Establishing successful microenterprises, Kerala experience. Human Networks Publication. Cleveland, Ohio.

Nair, S., T. Pesek \& L. Helton. 2007b. Ayurveda: Wisdom of life. Pp. 73-80 in Healing Traditions of India. Edited by T. Pesek, L. Helton, R. Reminick \& M. Nair. Olive Publications, Kerala.

Pesek, T., M. Cal, V. Cal, N. Fini, C. Minty, P. Dunham \& J. Arnason. 2006a. Rapid ethnobotanical survey of the Maya mountains range in Southern Belize: A pilot study. Trees for Life Journal 1(10):1-12.
Pesek, T., L. Helton \& M. Nair. 2006b. Healing across cultures: Learning from traditions. EcoHealth Journal 3(2):114-118.

Pesek, T., V. Cal, N. Fini, J. Cal, M. Rojas, P. Sanchez, L. Poveda, S. Collins, K. Knight \& J. Arnason. 2007c. Itzama: Revival of traditional healing by the Q'eqchi' Maya of Southern Belize. HerbalGram 76:34-43.

Pesek, T., L. Helton, R. Reminick \& M. Nair. 2007a.Editors of Healing Traditions of India. Olive Publications, Kerala

Pesek, T., L. Helton, R. Reminick \& M. Nair. 2007b. Learning from traditions of India. Pp 9-15 in Healing Traditions of India. Edited by T. Pesek, L. Helton, R. Reminick \& M. Nair. Olive Publications, Kerala.

Scharfe, H. 1999. The doctrine of the three humors in traditional Indian medicine and the alleged antiquity of Tamil Siddha medicine. Journal of the American Oriental Society 119(4):609-629.

Stepp J., H. Castaneda \& S. Cervone. 2005. Mountains and biocultural diversity. Mountain Research and Development 25(3):223-227.

Sutherland W. 2003. Parallel extinction risk and global distribution of languages and species. Nature 423:276-279.

United Nations Food and Agricultural Organization. 2000. Global Forest Resources Assessment, 2000. FAO Forestry Paper 140. www.fao.org/forestry/fo/fra/main/. Accessed August 3, 2005.

Vaidyar, S. 2007. Siddha Vaidyam. Pp 61-72 in Healing Traditions of India. Edited by T. Pesek, L. Helton, R. Reminick \& M. Nair. Olive Publications, Kerala.

World Health Organization. 2002. WHO Traditional Medicine Strategy 2002-2005. World Health Organization, Geneva.

World Wildlife Fund. 2004. Living Planet Report 2004. World Wildlife Fund, Gland, Switzerland. 
